\title{
Right anterior cingulate cortical volume covaries with respiratory sinus arrhythmia magnitude in combat veterans
}

\author{
Steven H. Woodward, PhD; ${ }^{*}$ Danny G. Kaloupek, PhD; ${ }^{2-3}$ Marie Schaer, MD, PhD; ${ }^{4-5}$ Christelle Martinez, \\ MA; ${ }^{4}$ Stephan Eliez, MD $^{4,6}$ \\ ${ }^{1}$ Dissemination and Training Division, Department of Veterans Affairs (VA) Palo Alto Health Care System and \\ National Center for Posttraumatic Stress Disorder (PTSD), Palo Alto, CA; ${ }^{2}$ Behavioral Science Division, VA Boston \\ Healthcare System and National Center for PTSD, Boston, MA; ${ }^{3}$ Division of Psychiatry, Boston University School of \\ Medicine, Boston, MA; ${ }^{4}$ Department of Psychiatry, University of Geneva, Geneva, Switzerland; ${ }^{5}$ Signal Processing \\ Laboratory, Swiss Federal Institute of Technology, Lausanne, Switzerland; ${ }^{6}$ Department of Genetic Medicine and \\ Development, University of Geneva, Geneva, Switzerland
}

\begin{abstract}
Existing data suggest anterior cingulate cortex (ACC) plays a role in autonomic regulation. In persons with posttraumatic stress disorder (PTSD), autonomic regulation appears impaired and smaller mean ACC volume has been reported. This study examined relationships between ACC volume and the magnitude of respiratory sinus arrhythmia (RSA) in 77 U.S. combat veterans at rest, 40 of whom met criteria for PTSD. RSA magnitude did not differ in combat survivors with and without PTSD, which contradicts studies comparing civilians with PTSD to nontraumatized controls. RSA magnitude was positively correlated with right but not left hemisphere ACC volume. This finding was statistically independent of the presence or absence of PTSD.
\end{abstract}

Key words: autonomic denervation, cardiac chronotropy, gyrus cinguli, heart rate variability, insular cortex, magnetic resonance imaging, posttraumatic, respiratory sinus arrhythmia, stress disorders, vagotomy.

\section{INTRODUCTION}

This article conjoins two previously independent literatures of posttraumatic stress disorder (PTSD) investigation: studies of autonomic dysregulation and studies of structural compromise in the brain. The first laboratory indication of neurobehavioral maladaptation in PTSD was evidence of excessive (presumably sympathetic) activation in response to trauma reminders [1]. Research in this area has ramified to include consideration of diagnostic utility [2-3], genetic determination [4], and the role of the parasympathetic branch of the autonomic nervous system (ANS) [5-8]. In 1995, Bremner and colleagues showed that

Abbreviations: ACC $=$ anterior cingulate cortex, ANS = autonomic nervous system, BOLD = blood oxygen level dependent, CAPS = Clinician-Administered PTSD Scale, DOD $=$ Department of Defense, ECG = electrocardiogram, EMG = electromyogram, $\mathrm{ETOH}=$ comorbid alcohol abuse/dependence, fMRI = functional magnetic resonance imaging, $\mathrm{HR}=$ heart rate, $\mathrm{HRV}=$ HR variability, IBI = interbeat-interval, LF = low frequency, $\mathrm{MAP}=$ mean arterial pressure, $\mathrm{MR}=$ magnetic resonance, $\mathrm{NS}=$ nonsignificant, $\mathrm{PET}=$ positron emission tomography, $\mathrm{PFC}=$ prefrontal cortex, $\mathrm{PTSD}=$ posttraumatic stress disorder, $\mathrm{rCBF}=$ regional cerebral blood flow, RSA = respiratory sinus arrhythmia, SCID = Structured Clinical Interview for the Diagnostic and Statistical Manual of Mental Disorders-Fourth Edition, TSST = Trier Social Stress Test, VA = Department of Veterans Affairs, VAPAHCS = VA Palo Alto Health Care System, WAIS-III = Wechsler Adult Intelligence Scale-Third Edition.

*Address all correspondence to Steven H. Woodward, PhD; VAPAHCS, 334 PTSD, 3801 Miranda Ave, Palo Alto, CA 94304; 650-493-5000, ext 22111; fax: 650-617-2701. Email: steve.woodward@va.gov

DOI: 10.1682/JRRD.2007.06.0082 
PTSD is associated with structural abnormality in the brain [9]. Studies in this arena have now found structural compromise in both hippocampus [10-15] and anterior cingulate cortex (ACC) [16-23] and have begun to address whether such compromise is inherited or acquired [13,23]. Evidence for functional compromise in ACC in PTSD is also substantial [24-31]. The possibility that these two literatures might intersect is evidenced by the fact that the ACC participates in regulating the cardiovascular system during cognitive, affective, and physical challenges. Data have come from neuroanatomical studies in animals, noninvasive neuroimaging studies in humans, and studies combining vagal nerve stimulation with neuroimaging in small samples of persons who are intractably depressed. Though focusing on the human studies, we will first briefly consider a compelling result in the rat.

\section{An Animal Study}

A small number of exacting studies have used pseudorabies virus, a transneuronal retrograde tracer that crosses functional synapses [32], to specify the multisynaptic relays in the central nervous system that participate directly in regulating the heart. In one such study, Ter Horst and Postema injected pseudorabies virus directly into the left ventricles of the hearts of rats [33]. By transecting the spinal cord at $\mathrm{T} 1$ (first thoracic vertebra), these authors precluded retrograde transport of the tracer to the brain by way of the sympathetic nerves. By promoting viral replication, they tracked the infection of neural tissue to the forebrain and identified cortical units that participated in cardiac regulation by way of the vagus nerve, the major efferent and afferent conduit of the parasympathetic branch of the ANS. At the top of this relay, they found "vagal command motoneurons" to be layer V pyramidal cells situated in the ACC, bilaterally. These findings provide strong evidence that the ACC in the rat participates in vagal regulation of the heart and perhaps of other end organs [34-35].

\section{Human Studies}

\section{Blood Pressure}

A growing number of neuroimaging studies support a role for the ACC in partnership with the insula in regulating the human cardiovascular system. Critchley, Gianaros, and their colleagues have been especially active in this area [36-40]. Using positron emission tomography (PET),
Critchley et al. observed in six participants that regional cerebral blood flow (rCBF) in the right dorsal ACC (Brodmann's areas 32 and 24) and right posterior insular cortex covaried directly with mean arterial pressure (MAP) during physical and mental challenge [36]. Gianaros et al. observed a similar finding using functional magnetic resonance (MR) imaging (fMRI) in a sample of 20 older adults (mean age 64) [37]: Stroop-task-driven systolic and diastolic blood pressure increases were correlated with Stroop-driven blood oxygen level dependent (BOLD) responses in bilateral dorsal and pregenual ACC (Brodmann's areas 32 and 24) and anterior and middle insula, bilaterally. In this study, positive covariation with MAP was also exhibited by activations in dorsolateral prefrontal cortex (PFC); supplementary motor area; and sections of temporal, parietal, and occipital cortices. In a follow-up study of 46 postmenopausal women, Gianaros et al. demonstrated that, across individuals, those participants with larger blood pressure responses exhibited larger BOLD activations in left pregenual ACC (in this case, anterior portions of Brodmann's area 32, excluding area 24), left insula, and right posterior cingulate cortex (Brodmann's area 31) [38].

\section{Heart Rate}

In their PET study just mentioned, Critchley et al. also assessed covariation of rCBF and heart rate (HR) during physical and mental challenges [36]. They obtained positive correlations in (relatively anterior) right insula (Talairach coordinates $=28,14,6$ ) and negative correlations in right middle frontal gyrus, right dorsal ACC, and posterior cingulate cortex (Brodmann's areas 24, 23, 31, respectively), bilateral (relatively posterior) insula, and bilateral orbitofrontal cortex (Brodmann's area 11). In a later study using an experimental design common in the PTSD literature, Critchley et al. elicited HR responses using emotional stimuli (faces) in a sample of 15 participants and found that the magnitudes of these responses were positively associated with BOLD activations in a network of regions including dorsal ACC, insula, and amygdale [39]. Gianaros et al. combined PET imaging and concurrent electrocardiogram (ECG) recording in a large sample $(N=93)$ of adults engaged in a series of increasingly difficult working memory tasks [40]. They also observed increased HR to be associated with rCBF increases in right dorsal ACC (as well as ventromedial PFC and insular cortex) and rCBF decreases in bilateral subgenual ACC (and inferior parietal cortex). 
Heart Rate Variability and Respiratory Sinus Arrhythmia

Different subbands of the spectrum of HR variability (HRV) are thought to index different components of autonomic input to the heart, so they are natural targets of investigations of brain regions involved in autonomic control. Respiratory sinus arrhythmia (RSA) represents HR or interbeat-interval (IBI) variation synchronized to the respiratory cycle. It represents cyclic gating of vagal input to the sinoatrial node by input from respiratory drive centers to vagal motoneurons in the medulla [41]. In correspondence with the respiratory cycle, RSA is conventionally defined as HRV in the band from 0.15 to $0.40 \mathrm{~Hz}$. It is also referred to as high-frequency HRV. Again, Critchley, Gianaros, and their colleagues have provided data relevant to the question of whether ACC activation is systematically associated with variation in RSA [40,42]. Critchley and colleagues performed fMRI in six participants engaged in an attentional task with two levels of difficulty [42]. They found power in the RSA and low-frequency (LF) (0.05 to $0.15 \mathrm{~Hz})$ subbands to be correlated with the magnitudes of BOLD activations in bilateral dorsal and right genual ACC. Correlations were also observed with BOLD activations in inferior parietal, somatosensory, and superior temporal cortices. Critchley et al. interpreted their results to indicate ACC involvement in regulating the sympathetic limb of the ANS [42]. However, power in the LF band is also largely vagally mediated [41]. In their large PET study, Gianaros et al. found decreased RSA to be associated with decreased rCBF in ventromedial PFC (Brodmann's area 10), anterior to pregenual ACC, and with increased $\mathrm{rCBF}$ in the cerebellum [40]. Positive correlations between RSA and rCBF were not reported.

Though wholly consistent structural-functional correlations are difficult to discern from the studies just reviewed, they generally confirm that dorsal and perigenual ACC, neocortical regions proximal to ACC, and insular cortex are the primary cortical regions contributing to autonomic regulation of the cardiovascular system in humans. Evidence was reviewed in the previous paragraphs that PTSD is associated with structural and functional compromise of ACC. Perhaps ACC hypofunction can partially account for features of autonomic dysregulation associated with this diagnosis. The present test of this possibility is limited. First, it relies on the assumption that the volume of a brain region represents an imperfect index of its functional capacity. Second, it assumes that resting RSA magnitude is a useful index of adaptive ver- sus maladaptive autonomic regulation in PTSD, a notion which has not been proven or universally accepted [41]. RSA magnitude is only one of many autonomic indexes of interest in this connection and certainly not the index that has been most frequently considered. RSA magnitude is of special interest here, however, because it is thought to specifically manifest the parasympathetic branch of the ANS, which has been studied less in PTSD, whereas all other easily measurable cardiovascular indexes represent combined parasympathetic and sympathetic efference in unknown proportions. In addition, growing evidence points to RSA magnitude as a prognostic indicator and/or mediating variable in a range of disease states for which persons with trauma and/or PTSD may be at increased risk [43-48].

One must observe certain cautions, however, when employing RSA as an index of vagal or parasympathetic tone [41]. Ideally, participants should be at rest in a seated or supine posture and refrain from speaking. Respiratory influences on HR effectively saturate at high respiratory frequencies. Speaking introduces HR variations unrelated to vagal modulation, and nonstationary components into the behavior of both the index (HR) and the underlying driver (respiration). Comparisons of RSA magnitude have yielded mixed results in PTSD and control groups assessed during speaking [6-7,49]. Using relatively long (15 to 20 minutes) at-rest recordings, Cohen et al. found RSA magnitudes to be reduced in two independent samples of civilian patients with PTSD compared with nonill controls (trauma histories unreported) $[6,50]$.

In view of studies implicating ACC in the parasympathetic limb of autonomic control of the heart, we predicted that the ACC volume would correlate with RSA magnitude. The current study assessed RSA during four separate rest periods that totaled approximately 1 hour of recording. These two rest periods ("baseline" and "preparation") comprised subsections of two consecutive administrations of the Trier Social Stress Tests (hereafter, TSST 1 and TSST 2) on the afternoon before structural imaging. Repeated TSST administrations allowed estimation of habitation of hypothalamic-pituitary-adrenal and autonomic responses to a repeated social stressor in persons with PTSD+ (positive) versus controls, following a test of a model for smaller hippocampal volume in PTSD [51]. The study design also compared combat veterans with PTSD with those without PTSD, thus controlling for any effects of trauma exposure. Though participants remained quietly seated during these rest periods, we expected that 
anticipation of the upcoming TSST would exert some effect on their arousal status. We performed a partial test of this possibility by comparing the baseline and preparation periods (see next section).

\section{METHODS}

\section{Participants}

Participants were Vietnam and Persian Gulf war combat veterans. They met strict criteria regarding diagnostic status as well as the availability and quality of structural MR and TSST/ECG data. Ninety-nine participants met diagnostic and MR data-related criteria. Further details regarding recruitment, screening, and exclusion leading to this sample are available elsewhere [15]. Of these 99, 77 met additional ECG and TSST administration criteria. These latter criteria were as follows:

1. The first TSST began after $12 \mathrm{pm}$.

2. The first baseline period was at least 5 minutes long.

3. Both preparation periods were at least 7 minutes long.

4. All interview and serial subtraction task periods were at least 5 minutes.

5. Both serial subtraction tasks were completed.
These criteria assured homogeneity of circadian effects and TSST task structure across groups. One subject refused the TSST. Additional participants were excluded because their RSA values were artifactually elevated (see "RSA Estimation" section, next page). Participants provided written informed consent according to procedures of applicable institutional review boards. Completing participants were paid $\$ 100$.

In the final sample of 77, 40 participants with PTSD+ (of which 3 were female) met criteria for current PTSD after experiencing one or more military traumas and 37 participants with PTSD- (of which 3 were female) were without current or lifetime PTSD due to military or civilian trauma. Participants with positive diagnoses of comorbid alcohol abuse/dependence $(\mathrm{ETOH}+)$ were based on meeting lifetime, but not current, alcohol abuse or dependence criteria on the Structured Clinical Interview for the Diagnostic and Statistical Manual of Mental Disorders-Fourth Edition (DSM-IV) (SCID). Characteristics of the sample participants are summarized in Table 1.

Psychotropic medications were continued during participation. Of the participants with PTSD+, 77 percent were taking a psychotropic medication, 44 percent a selective serotonin reuptake inhibitor, and 25 percent an anticonvulsant/mood-stabilizing medication. Among participants with PTSD-, the respective percentages were 14,5 , and 3.

Table 1.

Subject diagnostic and psychometric characteristics of U.S. combat veterans $(N=77)$ who met criteria for current PTSD. Data presented as mean \pm standard deviation unless otherwise noted.

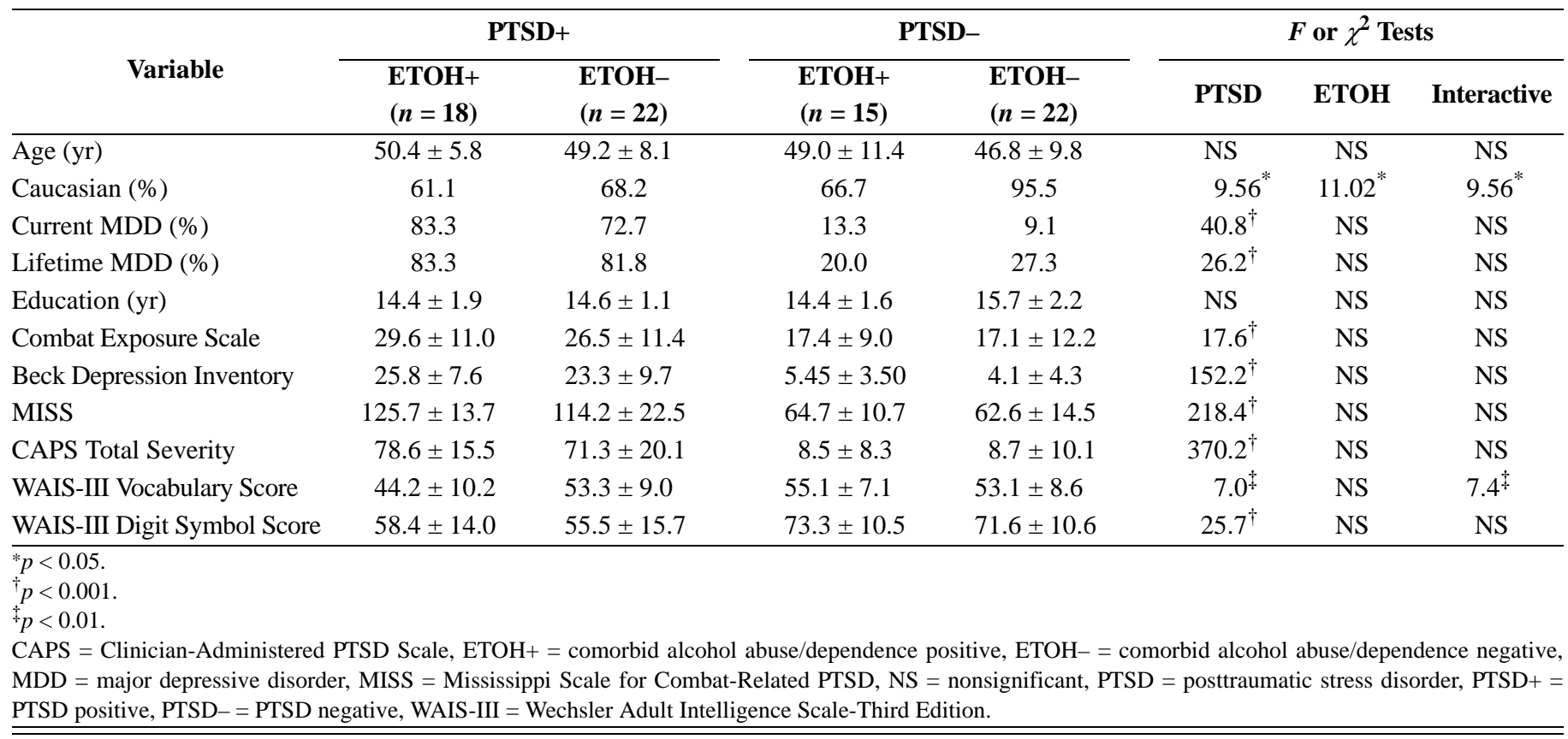




\section{Psychometrics}

Participants were administered the Clinician-Administered PTSD Scale (CAPS) [52] and selected Axis I modules of the SCID [53]. Verbal and nonverbal intellectual abilities were estimated using the vocabulary and digit symbol substitution subtests of the Wechsler Adult Intelligence ScaleThird Edition (WAIS-III) [54]. Additional self-report instruments included the Combat Exposure Scale [55], the Mississippi Scale for Combat-Related PTSD [56], and the Beck Depression Inventory [57].

\section{Trier Social Stress Test}

The TSST began with instructions to participants to prepare for a simulated job interview before an audience. This preparation period then lasted 7-10 minutes. The simulated interview lasted for 5 minutes and included inducements to continue speaking for the entire period. Participants were then asked to perform serial subtractions before the same audience for an additional $5 \mathrm{~min}$ utes. If arithmetic errors occurred, participants were required to start over. In this study, the TSST was amended to include preinstruction baseline periods. The second of these fell between the two administrations of the TSST and lasted approximately 40 minutes.

\section{Respiratory Sinus Arrhythmia Estimation}

During the TSSTs, participants were seated and quiet during both the preparation and baseline periods, which provided optimal conditions for estimating RSA. ECG was continuously recorded from gold electrodes located near the right clavicle and the left ninth rib, analog prefiltered to 1 to $100 \mathrm{~Hz}$, and digitized at $400 \mathrm{~Hz}$. ECG was later digitally filtered to a 5 to $100 \mathrm{~Hz}$ bandwidth and remapped to an instantaneous IBI time series with $0.04 \mathrm{~Hz}$ resolution. RSA estimates were derived every minute from Welch periodograms applied to the instantaneous IBI series (single epochs, Hamming-windowed) and were the sum of coefficient magnitudes from 0.15 to $0.40 \mathrm{~Hz}$. RSA magnitudes were estimated for each rest period by the median of all 1-minute epochs wholly contained within each period. In view of the sensitivity of RSA to artifact [58], four stages of exclusion were applied to the ECG/RSA data set, which totaled approximately 77 hours. Automated artifact detection was applied to individual $R$-waves and to 1-minute IBI series. Manual artifact screening was then applied to both IBI periodograms (HRV spectra) and to per period values of RSA magnitude. Most artifacts were due to contamination of the ECG by intracostal electromyogram (EMG). Six participants were excluded because their per period values of RSA magnitude were more than 2 standard deviations away from the group mean for one of the four periods of interest. Two of these participants were PTSD+ and four PTSD- (chi-square test was nonsignificant [NS], $\chi_{1}^{2}=$ 0.85). Of those excluded, their medical records did not note cardiological disease and their ECGs were not contaminated by premature ventricular contractions.

\section{Brain Imaging}

We performed magnetic resonance imaging using 1.5 T General Electric Signa scanners (GE Healthcare Technologies; Milwaukee, Wisconsin) at similar hardware and software revisions. One system was housed at the Diagnostic Radiology Center of the Department of Veterans Affairs (VA) Palo Alto Health Care System (VAPAHCS) and one at the Brain Imaging Center of McLean Hospital (Belmont, Massachusetts). Coronal images were acquired with a three-dimensional volumetric pulse sequence (relaxation time $=35 \mathrm{~ms}$, excitation time $=6 \mathrm{~ms}$, flip angle $=45^{\circ}$, number of excitations $=1$, matrix size $=$ $256 \times 192$, field of view $=24 \mathrm{~cm}^{2}$, slice thickness $=1.5-$ $1.7 \mathrm{~mm}$ with 124 slices). Image optimization was performed in BrainImage (A. L. Reiss; BrainImage v 5.x; Stanford University, Stanford, California) following the standard protocols of the Stanford Psychiatry Neuroimaging Laboratory [59-61].

We manually delineated the cingulate cortex following a protocol developed by one of the authors [17]. Cingulate gyri were first traced in sagittal view. We then used a coronal view to draw the superior, inferior, lateral, and medial, boundaries of the cingulate cortex and adjacent white matter. As in other studies [62-64], substantial intersubject variability was noted in rostral ACC landmarks. In our view, these precluded reliable delineation of subgenual cingulate cortex. This exclusion is noteworthy because multiple fMRI studies have now suggested that subgenual ACC, among ACC subregions, may have special relevance to PTSD [65]. After delineation, we fitted a dynamic Talairach grid on each brain, which subdivided the cingulate (Figure 1). Talairach sectors corresponding to $\mathrm{B}, \mathrm{C}, \mathrm{D}$, and $\mathrm{E} 1$ defined the anterior portion of the cingulate, while sectors E2, E3, F, G, and $\mathrm{H}$ defined the posterior cingulate. Two authors blind to subject identity and diagnosis performed all manual tracing. Cingulate tissue volumes (gray matter plus white matter) were highly reliable (intraclass correlation coefficient $=0.94$ ). Cross-laboratory reliability results, when conservatively interpreted, did not support the analysis of segmented gray 


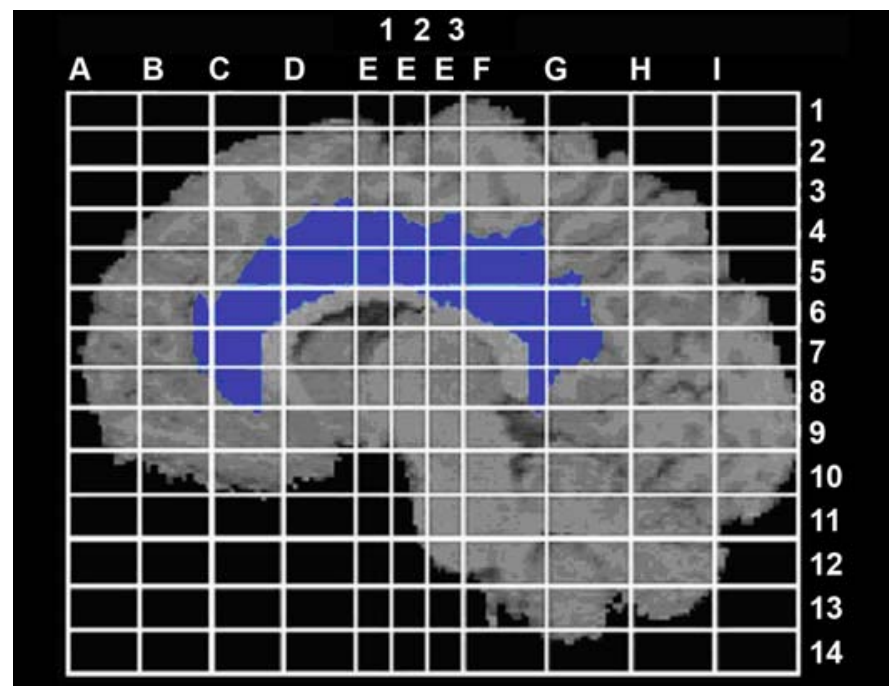

Figure 1.

Sagittal view of cingulate region of human brain with a Talairach grid superimposed in accordance with standard locators.

and white matter volumes in this data set [15]. Further details of image optimization and cingulate delineation are available elsewhere [17].

\section{RESULTS}

As presented in Table 1, this sample of U.S. combat veterans exhibited commonly observed features of elevated depressive comorbidity and mildly reduced estimated intellectual ability [66]. Because the sample was originally constructed to address associations with comorbid alcoholism, no excess of this diagnosis existed. Comorbid alcoholism interacted with PTSD in association with decreased WAIS-III vocabulary scores. Overall, this subsample of 77 participants appeared to represent the larger sample of 99 participants from which it was drawn $[15,17,67]$. In particular, the association between PTSD and ACC tissue volume persisted $\left(F_{1,72}=19.1, p<0.001\right)$ in the absence of any effect $\left(F_{1,72}=0.84\right.$, NS) or interaction $\left(F_{1,72}=0.06\right.$, NS) involving comorbid alcoholism [15]. As before, ACC tissue volume was larger on the right than on the left $\left(F_{1,72}=6.71, p<0.05\right)$ and exhibited no association with age $\left(r_{75}=0.025\right.$, NS).

HRV spectra did not exhibit the prominent elevations in the respiratory band typically associated with paced breathing or sleep (Figure 2). Nevertheless, RSA magnitudes (the sum of coefficient magnitudes between 0.15 and $0.40 \mathrm{~Hz}$ ) were normally distributed, and the expected negative associations of RSA with age were observed $(r=-0.41$ to $-0.54, p<0.001)$ [68]. Assessed with univariate repeated measures analysis of variance, RSA magnitude exhibited no effects of PTSD (least squares means adjusted for age: $\mathrm{PTSD}+=3.35 \mathrm{~ms} / \mathrm{Hz}$, PTSD- = $3.66 \mathrm{~ms} / \mathrm{Hz} ; F_{1,72}=0.87$, NS), comorbid alcoholism $\left(\mathrm{ETOH}+=3.66 \mathrm{~ms} / \mathrm{Hz}, \mathrm{ETOH}-=3.35 \mathrm{~ms} / \mathrm{Hz} ; F_{1,72}=\right.$ 0.85 , NS), or their interaction $\left(F_{1,72}=0.80\right.$, NS). Additionally, we found no effect of session (TSST 1 vs TSST 2; $F_{1,72}=1.2$, NS), no effect of phase (baseline vs preparation; $F_{1,72}=1.2$, NS), and no interaction of session and phase $\left(F_{1,72}=0.002\right.$, NS). Grouping factors did not interact with within-group factors. HR also exhibited no effects of PTSD (least squares means: PTSD $+=77.1 \mathrm{bpm}$, PTSD- $=77.8$ bpm; $F_{1,72}=0.07$, NS), comorbid alcoholism $\left(\mathrm{ETOH}+=79.0 \mathrm{bpm}, \mathrm{ETOH}-=75.8 \mathrm{bpm} ; F_{1,72}=\right.$ 1.65 , NS), or their interaction $\left(F_{1,72}=0.13\right.$, NS).

First-order Pearson product moment correlations between RSA magnitudes and ACC tissue volumes are presented in Table 2. Of interest in this table is the appearance of medium-sized positive correlations between right ACC tissue volumes and RSA magnitudes that were significant in three cases and nearly significant in the fourth. In contrast, left hemisphere ACC tissue volume exhibited no correlations with RSA magnitude. The correlation of left and right ACC tissue volumes was $r=$ $0.32(p<0.01)$ which, though statistically significant, implied that their shared variance was less than 10 percent of their individual variances. This low level of volumetric correlations is compatible with their apparently divergent relations to RSA magnitude. RSA magnitudes from the different sessions and phases were highly correlated with one another $(r=0.79-0.86, p<0.001)$. However, the TSST 2 baseline period was the longest of the four and presumably yielded the most reliable single estimate of RSA magnitude. Figure 3 presents bivariate plots of TSST 2 baseline RSA magnitude by left and right ACC volumes. Inspection of these plots indicated that outliers did not influence the observed pattern of correlations. This pattern of results was preserved in a weakened form in PTSD+ and PTSD- subgroups assessed separately. All eight correlations between right ACC tissue volume and RSA magnitude were positive, and four were significant. All eight correlations between left ACC tissue volume and RSA magnitude were negative, and none was significant. 
(a)
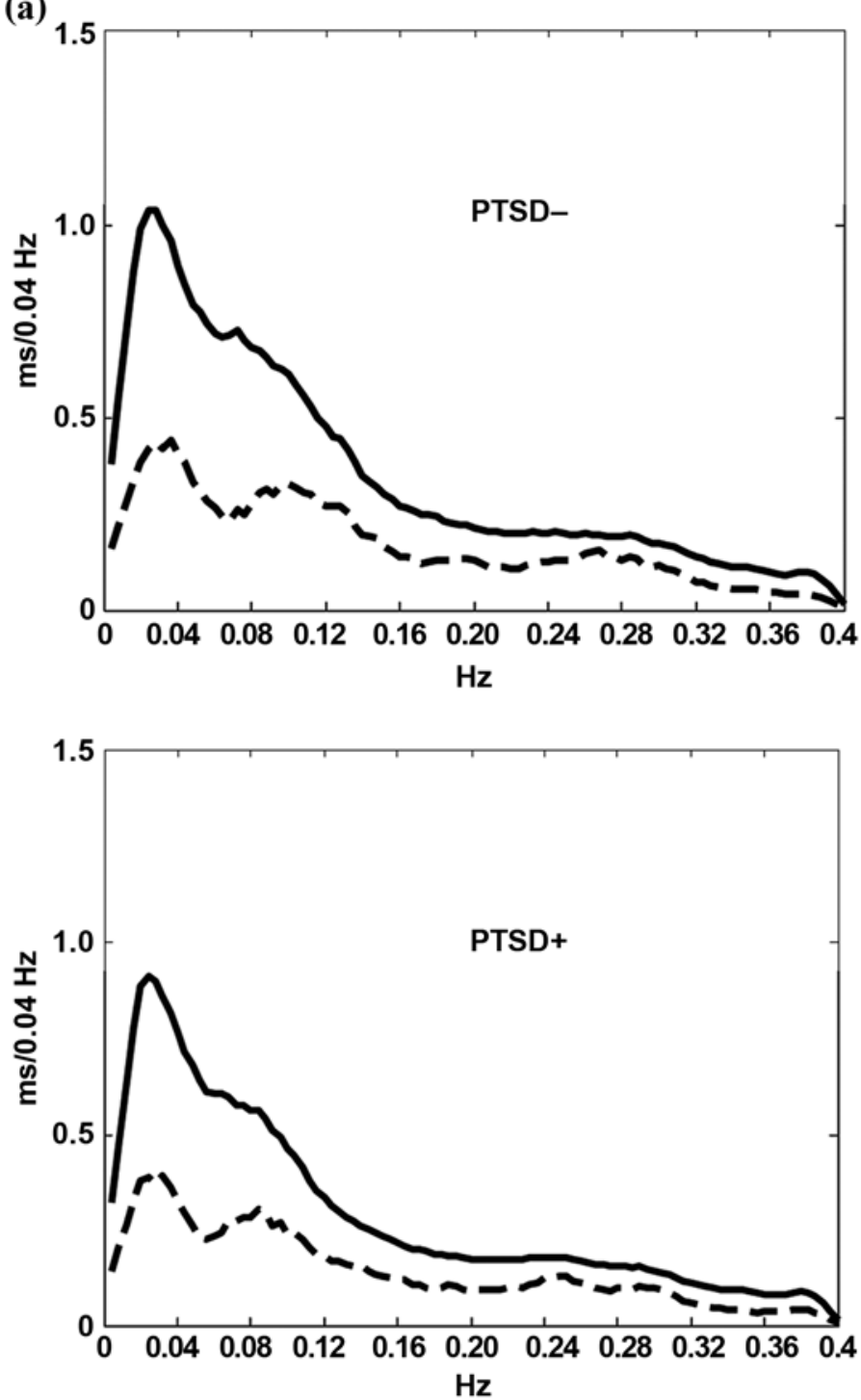

(b)
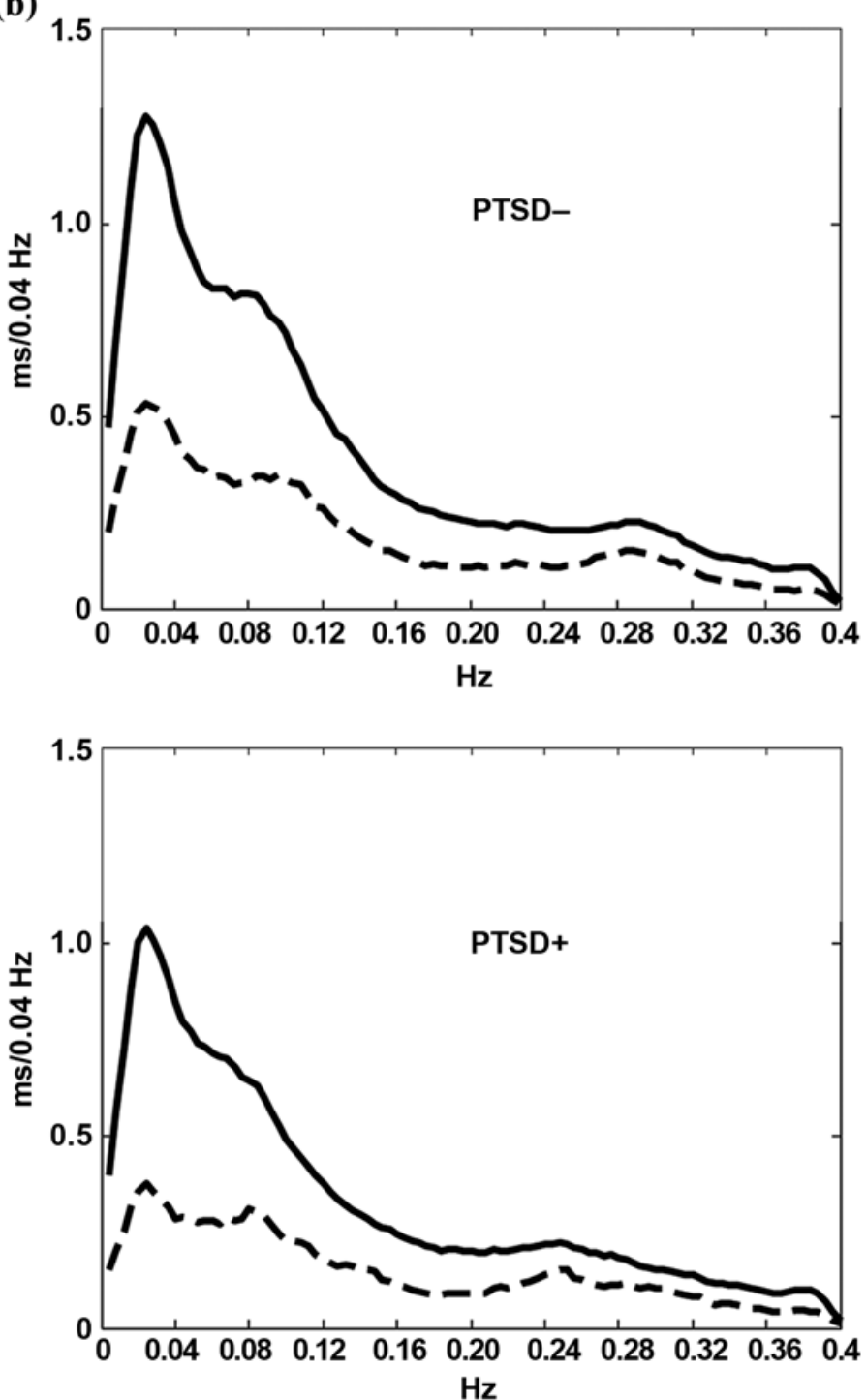

Figure 2.

Heartbeat variability spectra derived from baseline periods of first and second administrations of (a) Trier Social Stress Test (TSST) 1 and (b) TSST 2 for participants (U.S. combat veterans [ $N=77]$ ) with posttraumatic stress disorder positive (PTSD+) and PTSD negative (PTSD-). Solid lines are mean spectral coefficients; dotted lines are standard deviations of spectral coefficients. No effects of PTSD diagnosis, test session (1 vs 2), or phase (baseline vs preparation — not depicted) were found. Note that conditions of this experiment did not induce prominent respiratory sinus arrhythmia peaks in combat-exposed participants with and without PTSD who were ostensibly at rest.

As noted earlier, RSA magnitude is strongly associated with age. Hence, we used hierarchical regression to determine whether the same pattern of results was obtained with age contribution controlled. Entering left and right ACC volumes as predictors of TSST 2 baseline RSA magnitude in the second step of this model resulted in a significant increment in $R^{2}$ (0.49 to 0.58 , incremental $\left.F_{2,73}=5.23, p<0.008\right)$. Again, however, right but not left hemisphere ACC tissue volume accounted for significant variance in RSA magnitude (right: $\beta=0.33, t=$ 3.22, $p<0.002$; left: $\beta=-0.08, t=0.84$, NS). Repeating this analysis in the PTSD+ and PTSD- groups separately produced similar results. In both cases, the $R^{2}$ increment was nearly significant ( $p=0.09$ and 0.12 , respectively) and right but not left hemisphere ACC volume accounted for significant variance in TSST 2 baseline RSA 
magnitude (PTSD+ right: $\beta=0.32, t=2.23, p<0.032$; left: $\beta=-0.04, t=0.28$, NS; PTSD- right: $\beta=0.30, t=$ 2.08, $p<0.045$; left: $\beta=-0.12, t=0.79$, NS).

The results of these analyses present a strikingly similar pattern of divergent relationships between left and right ACC tissue volumes and RSA magnitude in participants with PTSD+ and PTSD-. At the same time, both left and right hemisphere ACC tissue volumes were smaller in

Table 2.

Pearson product moment correlations between left and right hemisphere anterior cingulate cortex (ACC) tissue volumes and respiratory sinus arrhythmia magnitudes across baseline and preparation periods from Trier Social Stress Tests (TSSTs) 1 and 2. As noted in text, these values are based on ACC volume estimates that exclude subgenual tissue.

\begin{tabular}{cccccc}
\hline $\begin{array}{c}\text { Hemisphere } \\
\text { ACC Tissue } \\
\text { Volume }\end{array}$ & \multicolumn{2}{c}{ TSST 1 } & & \multicolumn{2}{c}{ TSST 2 } \\
\cline { 2 - 3 } \cline { 5 - 6 } \cline { 5 - 6 } Left & 0.00 & -0.10 & & -0.06 & -0.10 \\
Right & 0.22 & $0.25^{*}$ & & $0.35^{\dagger}$ & $0.33^{\dagger}$ \\
\hline${ }^{*} p<0.05$. & & & & \\
${ }^{\dagger} p<0.01$. & & & & \\
\hline \hline
\end{tabular}

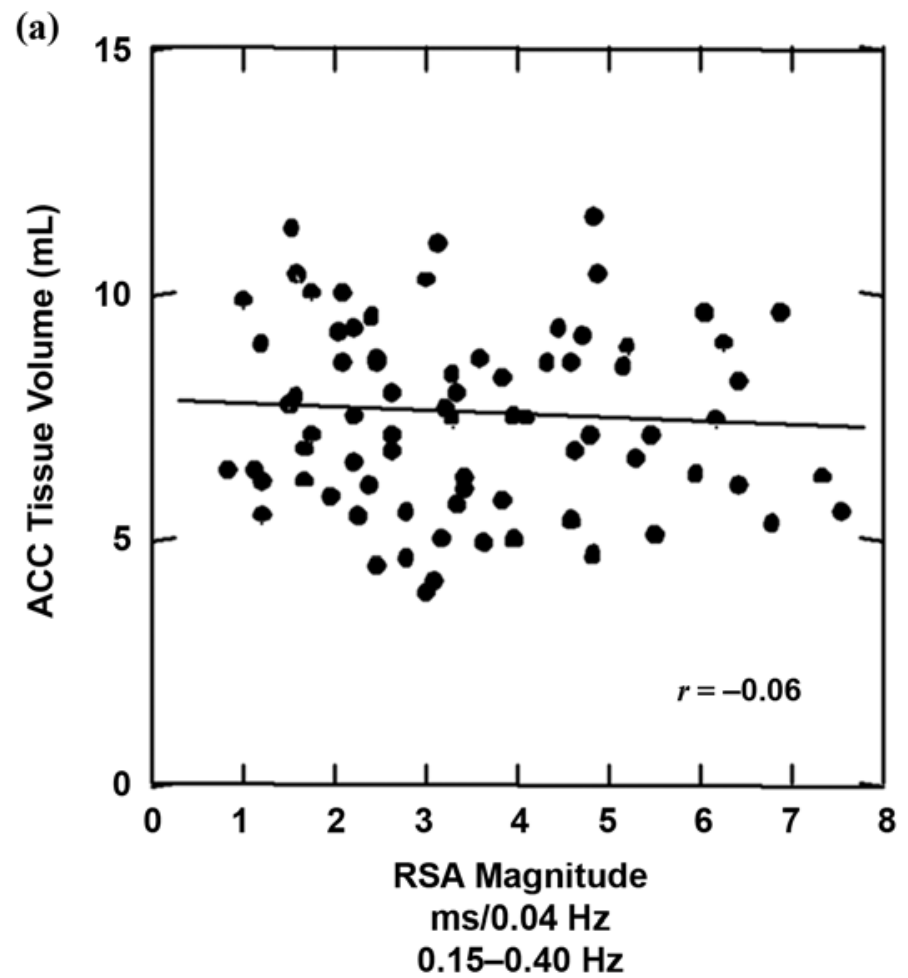

PTSD, exhibiting, in this sample, comparable effect sizes (left: partial $\eta^{2}=0.15$; right: partial $\eta^{2}=0.12$ ). Hence, our interest was to determine whether residualizing left and right ACC tissue volumes against PTSD (by using CAPS total severity score) left the pattern intact. In a hierarchical regression, after entering age, right but not left ACC tissue volume residual again accounted for significant variance in TSST 2 baseline RSA magnitude (right: $\beta=0.28, t=2.80$, $p<0.007$; left: $\beta=-0.069, t=0.67$, NS). Conversely, residualizing left and right hemisphere ACC volumes against RSA magnitude left the PTSD group difference intact.

\section{DISCUSSION}

This study examined linear relationships between ACC tissue volume and RSA magnitude. The findings suggested that ACC tissue volume in the right hemisphere could account for significant variance in RSA magnitude during the quiet periods of the TSST. The shared variance between

(b)

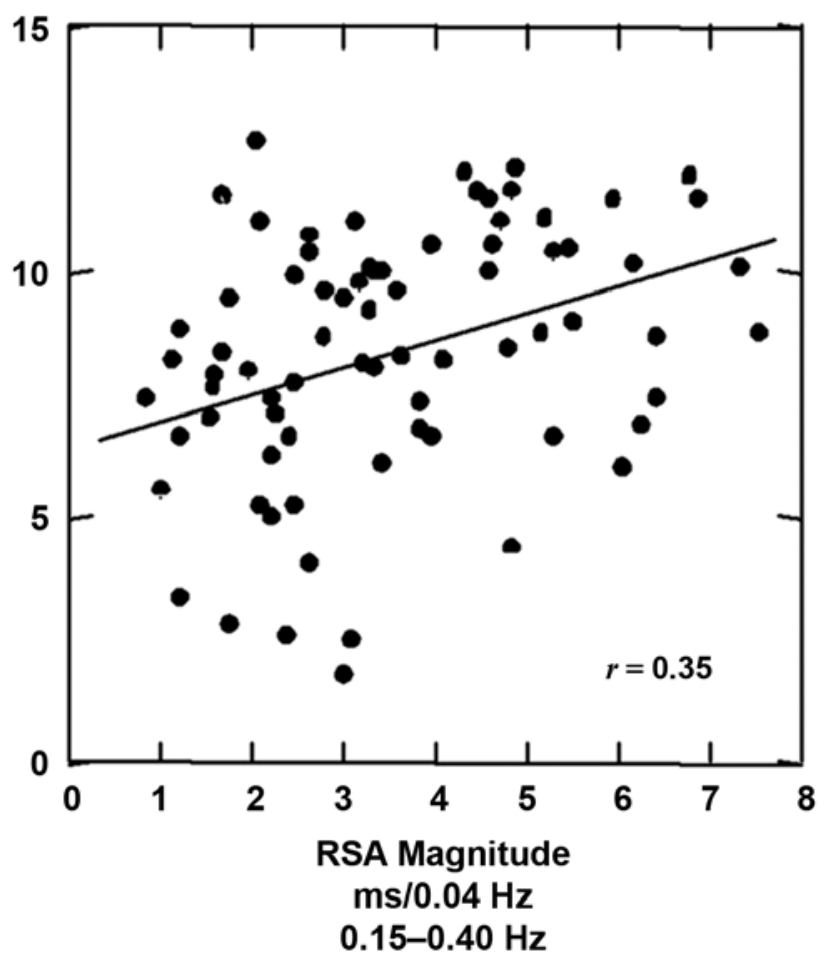

Figure 3.

Bivariate scatterplots of respiratory sinus arrhythmia (RSA) magnitude ( $x$-axis) by left and right anterior cingulate cortex (ACC) tissue volumes (y-axis) of the Trier Social Stress Test 2. RSA magnitudes were based upon longer (40 min) baseline period preceding second administration. 
ACC tissue volume and RSA appeared to be largely independent of the variance in ACC volume associated with PTSD. Furthermore, the specific association of right hemisphere ACC volume with RSA magnitude was apparent in both PTSD+ and PTSD- groups. An important qualification regarding all of these observations is that subgenual ACC volume was not quantified out of concern that it could not be done reliably. As noted, multiple fMRI studies have now implicated subgenual ACC in PTSD [65].

The finding of a positive relationship between ACC tissue volume and RSA magnitude is generally compatible with evidence reviewed in the "Introduction" section (p. 451) implicating ACC in autonomic regulation. However, this interpretation again relies on the assumption that the volume of a brain region represents a plausible estimator of its functional capacity when, in fact, multiple intrinsic structural characteristics are likely to be at least as important. As well, our results are purely correlative. In fact, the usual caveats regarding the indeterminacy of causation given correlation are reinforced by the findings of Critchley et al. [69]. Using voxel-based morphometry, they observed that peripheral autonomic denervation was associated with reduced gray matter density in the ACC and insula, a pattern seen in other denervation syndromes [69]. This finding suggests that the observed pattern of results could have emerged if a third mechanism induced a pattern of functional autonomic denervation resulting in both smaller right ACC volume and lower RSA magnitude that were then adventitiously correlated.

We observed no PTSD diagnostic group differences in RSA magnitude at rest despite using subject and behavior samples two to four times as large as those used by two prior studies reporting positive findings [6,50]. Our findings are therefore more compatible with those of Sahar et al. [7], who also found no effect of PTSD on resting RSA. One limitation of the current design was the temporal association of the baseline and preparation periods with challenging social stressors. Temporal association with stress testing could have aroused subjects and so restricted the upper range of RSA magnitude. However, HRs were only mildly elevated [70] and also exhibited no effects of diagnosis. Also noteworthy is that the high data quality requirements for accurate RSA estimation could have excluded subjects whose ECG records are excessively contaminated with EMG and/or movement artifact. Exclusion of presumably more aroused subjects could have restricted the lower range of the RSA distribution. If the range of RSA magnitude had been restricted in this study, associations with ACC tissue volumes may have been attenuated. In sum, the current observations may represent a "minimal result" involving a static structural probe of ACC status and perhaps a range-restricted index of tonic autonomic adaptation. More illuminating findings may come from studies combining functional neuroimaging with concurrent recording of autonomic indexes. A number of the Critchley and Gianaros designs could be applied to PTSD samples with little modification.

\section{CONCLUSIONS}

Consistent with existing evidence implicating forebrain cortical regions in cardiac regulation, the findings of this initial investigation of ACC volume and RSA magnitude in combat veterans suggest that a smaller ACC is associated with less parasympathetic regulation of HR. Further studies in this area can be expected to provide additional neurobehavioral insights into morbidity and mortality among those exposed to traumatic stressors such as military combat.

\section{ACKNOWLEDGMENTS}

Special thanks are due to Stephen Grate and Lori Moll who facilitated the necessary arrangements at the Department of Defense (DOD) institutions. We wish also to thank the Research Services of the VAPAHCS and VA Boston Healthcare System for their support. Institutional and technical support was provided by John E. Drace, Patricia Spezia, Carla Ambriz, and Gary E. Gold of VAPAHCS, Palo Alto, California; Kelly Teresi, Frederick Kanter, Steven Blank, Susan Proctor, and Erica Stone of VA Boston Healthcare System, Boston, Massachusetts; Thomas J. Brosnan, Anil Patwardhan, and Eric Schmitt of Stanford University, Stanford, California; Rosemond Villafuerte, Ann Smith, and Eileen Connolly of McLean Hospital, Belmont, Massachusetts; and Micheal A. Dove of Defense Manpower Database Center, Arlington, Virginia. We are also grateful for the guidance provided by Kelvin O. Lim, Allan L. Reiss, Perry F. Renshaw, and Lawrence L. Wald. Finally, we wish to thank Ned Arsenault, Lorraine Leskin, Rebecca Prestel, Catherine Kutter, and Wendy Stegman for their excellent technical support of this work. 
This material was based in part on work supported by grants from Swiss National Research Funds to Dr. Schaer, 323500-111165, and to Dr. Eliez, 3200-063135, 3232063134, and PP00B-102864, and a grant from National Alliance for Research on Schizophrenia and Depression to Dr. Eliez. This material was also supported by a VA and DOD assistance agreement to Drs. Woodward and Kaloupek from the U.S. Army Medical Research and Materiel Command (DOD) administered through the Institute for Medical Research (VA).

The authors have declared that no competing interests exist.

\section{REFERENCES}

1. Dobbs D, Wilson WP. Observations on persistence of war neurosis. Dis Nerv Syst. 1960;21:686-91. [PMID: 13723233]

2. Keane TM, Kolb LC, Kaloupek DG, Orr SP, Blanchard EB, Thomas RG, Hsieh FY, Lavori PW. Utility of psychophysiological measurement in the diagnosis of posttraumatic stress disorder: results from a Department of Veterans Affairs Cooperative Study. J Consult Clin Psychol. 1998; 66(6):914-23. [PMID: 9874904]

3. Shalev AY, Sahar T, Freedman S, Peri T, Glick N, Brandes D, Orr SP, Pitman RK. A prospective study of heart rate response following trauma and the subsequent development of posttraumatic stress disorder. Arch Gen Psychiatry. 1998; 55(6):553-59. [PMID: 9633675$]$

4. Orr SP, Metzger LJ, Lasko NB, Macklin ML, Hu FB, Shalev AY, Pitman RK; Harvard/Veterans Affairs Post-traumatic Stress Disorder Twin Study Investigators. Physiologic responses to sudden, loud tones in monozygotic twins discordant for combat exposure: association with posttraumatic stress disorder. Arch Gen Psychiatry 2003;60(3):283-88. [PMID: 12622661]

5. Griffin MG, Resick PA, Mechanic MB. Objective assessment of peritraumatic dissociation: psychophysiological indicators. Am J Psychiatry. 1997;154(8):1081-88. [PMID: 9247393]

6. Cohen H, Benjamin J, Geva AB, Matar MA, Kaplan Z, Kotler M. Autonomic dysregulation in panic disorder and in post-traumatic stress disorder: application of power spectrum analysis of heart rate variability at rest and in response to recollection of trauma or panic attacks. Psychiatry Res. 2000;96(1):1-13. [PMID: 10980322]

7. Sahar T, Shalev AY, Porges SW. Vagal modulation of responses to mental challenge in posttraumatic stress disorder. Biol Psychiatry. 2001;49(7):637-43. [PMID: 11297721]

8. Hopper JW, Spinazzola J, Simpson WB, Van der Kolk BA. Preliminary evidence of parasympathetic influence on basal heart rate in posttraumatic stress disorder. J Psychosom Res. 2006;60(1):83-90. [PMID: 16380314]

9. Bremner JD, Randall P, Scott TM, Bronen RA, Seibyl JP, Southwick SM, Delaney RC, McCarthy G, Charney DS, Innis RB. MRI-based measurement of hippocampal volume in patients with combat-related posttraumatic stress disorder. Am J Psychiatry. 1995;152(7):973-81. [PMID: 7793467]

10. Gurvits TV, Shenton ME, Hokama H, Ohta H, Lasko NB, Gilbertson MW, Orr SP, Kikinis R, Jolesz FA, McCarley RW, Pitman RK. Magnetic resonance imaging study of hippocampal volume in chronic, combat-related posttraumatic stress disorder. Biol Psychiatry. 1996;40(11):1091-99. [PMID: 8931911]

11. Stein MB, Koverola C, Hanna C, Torchia MG, McClarty B. Hippocampal volume in women victimized by childhood sexual abuse. Psychol Med. 1997;27(4):951-59. [PMID: 9234472]

12. Villarreal G, Hamilton DA, Petropoulos H, Driscoll I, Rowland LM, Griego JA, Kodituwakku PW, Hart BL, Escalona R, Brooks WM. Reduced hippocampal volume and total white matter volume in posttraumatic stress disorder. Biol Psychiatry. 2002;52(2):119-25. [PMID: 12114003]

13. Gilbertson MW, Shenton ME, Ciszewski A, Kasai K, Lasko NB, Orr SP, Pitman RK. Smaller hippocampal volume predicts pathologic vulnerability to psychological trauma. Nat Neurosci. 2002;5(11):1242-47. [PMID: 12379862]

14. Lindauer RJ, Vlieger EJ, Jalink M, Olff M, Carlier IV, Majoie CB, den Heeten GJ, Gersons BP. Smaller hippocampal volume in Dutch police officers with posttraumatic stress disorder. Biol Psychiatry. 2004;56(5):356-63. [PMID: 15336518]

15. Woodward SH, Kaloupek DG, Streeter CC, Kimble MO, Reiss AL, Eliez S, Wald LL, Renshaw PF, Frederick BB, Lane B, Sheikh JI, Stegman WK, Kutter CJ, Stewart LP, Prestel RS, Arsenault NJ. Hippocampal volume, PTSD, and alcoholism in combat veterans. Am J Psychiatry. 2006; 163(4):674-81. [PMID: 16585443]

16. Rauch SL, Shin LM, Segal E, Pitman RK, Carson MA, McMullin K, Whalen PJ, Makris N. Selectively reduced regional cortical volumes in post-traumatic stress disorder. Neuroreport. 2003;14(7):913-16. [PMID: 12802174]

17. Woodward SH, Kaloupek DG, Streeter CC, Martinez C, Schaer M, Eliez S. Decreased anterior cingulate volume in combat-related PTSD. Biol Psychiatry. 2006;59(7):582-87. [PMID: 16165099]

18. Kitayama N, Quinn S, Bremner JD. Smaller volume of anterior cingulate cortex in abuse-related posttraumatic stress disorder. J Affect Disord. 2006;90(2-3):171-74. [PMID: 16375974]

19. Yamasue H, Kasai K, Iwanami A, Ohtani T, Yamada H, Abe O, Kuroki N, Fukuda R, Tochigi M, Furukawa S, Sadamatsu M, Sasaki T, Aoki S, Ohtomo K, Asukai N, Kato N. Voxelbased analysis of MRI reveals anterior cingulate gray-matter 
volume reduction in posttraumatic stress disorder due to terrorism. Proc Natl Acad Sci U S A. 2003; 100(15):9039-43. [PMID: 12853571]

20. Chen S, Xia W, Li L, Liu J, He Z, Zhang Z, Yan L, Zhang $\mathrm{J}, \mathrm{Hu} \mathrm{D}$. Gray matter density reduction in the insula in fire survivors with posttraumatic stress disorder: a voxel-based morphometric study. Psychiatry Res. 2006;146(1):65-72. [PMID: 16371250]

21. Mahmutyazicioglu K, Konuk N, Ozdemir H, Atasoy N, Atik L, Gundogdu S. Evaluation of the hippocampus and the anterior cingulate gyrus by proton MR spectroscopy in patients with post-traumatic stress disorder. Diagn Interv Radiol. 2005;11(3):125-29. [PMID: 16206051]

22. De Bellis MD, Keshavan MS, Spencer S, Hall J. N-Acetylaspartate concentration in the anterior cingulate of maltreated children and adolescents with PTSD. Am J Psychiatry. 2000; 157(7):1175-77. [PMID: 10873933]

23. Kasai K, Yamasue H, Gilbertson MW, Shenton ME, Rauch SL, Pitman RK. Evidence for acquired pregenual anterior cingulate gray matter loss from a twin study of combatrelated posttraumatic stress disorder. Biol Psychiatry. 2008; 63(6):550-56. [PMID: 17825801]

24. Shin LM, McNally RJ, Kosslyn SM, Thompson WL, Rauch SL, Alpert NM, Metzger LJ, Lasko NB, Orr SP, Pitman RK. Regional cerebral blood flow during script-driven imagery in childhood sexual abuse-related PTSD: a PET investigation. Am J Psychiatry. 1999;156(4):575-84. [PMID: 10200737]

25. Bremner JD, Staib LH, Kaloupek D, Southwick SM, Soufer R, Charney DS. Neural correlates of exposure to traumatic pictures and sound in Vietnam combat veterans with and without posttraumatic stress disorder: a positron emission tomography study. Biol Psychiatry. 1999;45(7): 806-16. [PMID: 10202567]

26. Shin LM, Whalen PJ, Pitman RK, Bush G, Macklin ML, Lasko NB, Orr SP, McInerney SC, Rauch SL. An fMRI study of anterior cingulate function in posttraumatic stress disorder. Biol Psychiatry. 2001;50(12):932-42. [PMID: 11750889]

27. Lanius RA, Williamson PC, Hopper J, Densmore M, Boksman K, Gupta MA, Neufeld RW, Gati JS, Menon RS. Recall of emotional states in posttraumatic stress disorder: an fMRI investigation. Biol Psychiatry. 2003;53(3):204-10. [PMID: 12559652]

28. Liberzon I, Britton JC, Phan KL. Neural correlates of traumatic recall in posttraumatic stress disorder. Stress. 2003; 6(3):151-56. [PMID: 13129808]

29. Bremner JD, Vythilingam M, Vermetten E, Southwick SM, McGlashan T, Staib LH, Soufer R, Charney DS. Neural correlates of declarative memory for emotionally valenced words in women with posttraumatic stress disorder related to early childhood sexual abuse. Biol Psychiatry. 2003; 53(10):879-89. [PMID: 12742675]
30. Yang P, Wu MT, Hsu CC, Ker JH. Evidence of early neurobiological alternations in adolescents with posttraumatic stress disorder: A functional MRI study. Neurosci Lett. 2004; 370(1):13-18. [PMID: 15489009]

31. Shin LM, Wright CI, Cannistraro PA, Wedig MM, McMullin K, Martis B, Macklin ML, Lasko NB, Cavanagh SR, Krangel TS, Orr SP, Pitman RK, Whalen PJ, Rauch SL. A functional magnetic resonance imaging study of amygdala and medial prefrontal cortex responses to overtly presented fearful faces in posttraumatic stress disorder. Arch Gen Psychiatry. 2005;62(3):273-81. [PMID: 15753240]

32. Card JP, Rinaman L, Lynn RB, Lee BH, Meade RP, Miselis RR, Enquist LW. Pseudorabies virus infection of the rat central nervous system: ultrastructural characterization of viral replication, transport, and pathogenesis. J Neurosci. 1993; 13(6):2515-39. [PMID: 8388923]

33. Ter Horst GJ, Postema F. Forebrain parasympathetic control of heart activity: retrograde transneuronal viral labeling in rats. Am J Physiol. 1997;273(6 Pt 2):H2926-30. [PMID: 9435633]

34. Benarroch EE. The central autonomic network: functional organization, dysfunction, and perspective. Mayo Clin Proc. 1993;68(10):988-1001. [PMID: 8412366]

35. Neafsey EJ. Prefrontal cortical control of the autonomic nervous system: anatomical and physiological observations. Prog Brain Res. 1990;85:147-66. [PMID: 2094892]

36. Critchley HD, Corfield DR, Chandler MP, Mathias CJ, Dolan RJ. Cerebral correlates of autonomic cardiovascular arousal: a functional neuroimaging investigation in humans. J Physiol. 2000;523 Pt 1:259-70. [PMID: 10673560]

37. Gianaros PJ, Derbyshire SW, May JC, Siegle GJ, Gamalo MA, Jennings JR. Anterior cingulate activity correlates with blood pressure during stress. Psychophysiology. 2005;42(6): 627-35. [PMID: 16364058]

38. Gianaros PJ, Jennings JR, Sheu LK, Derbyshire SW, Matthews KA. Heightened functional neural activation to psychological stress covaries with exaggerated blood pressure reactivity. Hypertension. 2007;49(1):134-40. [PMID: 17101844]

39. Critchley HD, Rotshtein P, Nagai Y, O’Doherty J, Mathias CJ, Dolan RJ. Activity in the human brain predicting differential heart rate responses to emotional facial expressions. Neuroimage. 2005;24(3):751-62. [PMID: 15652310]

40. Gianaros PJ, Van Der Veen FM, Jennings JR. Regional cerebral blood flow correlates with heart period and highfrequency heart period variability during working-memory tasks: implications for the cortical and subcortical regulation of cardiac autonomic activity. Psychophysiology. 2004; 41(4):521-30. [PMID: 15189475]

41. Berntson GG, Bigger JT Jr, Eckberg DL, Grossman P, Kaufmann PG, Malik M, Nagaraja HN, Porges SW, Saul JP, Stone PH, Van Der Molen MW. Heart rate variability: 
origins, methods, and interpretive caveats. Psychophysiology. 1997;34(6):623-48. [PMID: 9401419]

42. Critchley HD, Mathias CJ, Josephs O, O’Doherty J, Zanini S, Dewar BK, Cipolotti L, Shallice T, Dolan RJ. Human cingulate cortex and autonomic control: converging neuroimaging and clinical evidence. Brain. 2003;126(Pt 10):2139-52. [PMID: 12821513]

43. Stein PK, Freedland KE, Skala JA, Carney RM, DavilaRoman V, Rich MW, Kleiger RE. Heart rate variability is independent of age, gender, and race in congestive heart failure with a recent acute exacerbation. Am J Cardiol. 1997;79(4):511-12. [PMID: 9052363$]$

44. Thayer JF, Lane RD. The role of vagal function in the risk for cardiovascular disease and mortality. Biol Psychol. 2007; 74(2):224-42. [PMID: 17182165]

45. Masi CM, Hawkley LC, Rickett EM, Cacioppo JT. Respiratory sinus arrhythmia and diseases of aging: obesity, diabetes mellitus, and hypertension. Biol Psychol. 2007;74(2):212-23. [PMID: 17034928]

46. Norman SB, Means-Christensen AJ, Craske MG, Sherbourne CD, Roy-Byrne PP, Stein MB. Associations between psychological trauma and physical illness in primary care. J Trauma Stress. 2006;19(4):461-70. [PMID: 16929502]

47. Violanti JM, Fekedulegn D, Hartley TA, Andrew ME, Charles LE, Mnatsakanova A, Burchfiel CM. Police trauma and cardiovascular disease: association between PTSD symptoms and metabolic syndrome. Int J Emerg Ment Health. 2006;8(4):227-37. [PMID: 17131769]

48. Kubzansky LD, Koenen KC, Spiro A 3rd, Vokonas PS, Sparrow D. Prospective study of posttraumatic stress disorder symptoms and coronary heart disease in the Normative Aging Study. Arch Gen Psychiatry. 2007;64(1):109-16. [PMID: 17199060]

49. Scheeringa MS, Zeanah CH, Myers L, Putnam F. Heart period and variability findings in preschool children with posttraumatic stress symptoms. Biol Psychiatry. 2004;55(7): 685-91. [PMID: 15065300]

50. Cohen H, Kotler M, Matar MA, Kaplan Z, Miodownik H, Cassuto Y. Power spectral analysis of heart rate variability in posttraumatic stress disorder patients. Biol Psychiatry. 1997;41(5):627-29. [PMID: 9046997]

51. McEwen BS, Magarinos AM. Stress effects on morphology and function of the hippocampus. Ann N Y Acad Sci. 1997;821:271-84. [PMID: 9238211]

52. Blake DD, Weathers FW, Nagy LM, Kaloupek DG, Charney DS, Keane TM. Clinician-administered PTSD scale for DSM-IV: Current and lifetime version. Boston (MA): Behavioral Science Division, Boston VA Medical Center/Neurosciences Division,West Haven VA Medical Center; 1997.

53. First MB, Spitzer RL, Gibbon M, Williams JB. Structured clinical interview for the DSM-IV Axis-I disorders. New
York (NY): Biometrics Research Department, New York State Psychiatric Institute; 1997.

54. Psychological Corporation. WAIS-III: Administration and scoring manual. 3rd ed. San Antonio (TX): Harcourt Brace; 1997.

55. Keane TM, Fairbank JA, Caddell JM, Zimering RT, Taylor KL, Mora CA. Clinical evaluation of a measure to assess combat exposure. Psychol Assess. 1989;1(1):53-55.

56. Keane TM, Caddell JM, Taylor KL. Mississippi Scale for Combat-Related Posttraumatic Stress Disorder: three studies in reliability and validity. J Consult Clin Psychol. 1988; 56(1):85-90. [PMID: 3346454]

57. Beck AT, Ward CH, Mendelson M, Mock J, Erbaugh J. An inventory for measuring depression. Arch Gen Psychiatry. 1961;4:561-71. [PMID: 13688369$]$

58. Berntson GG, Stowell JR. ECG artifacts and heart period variability: Don’t miss a beat! Psychophysiology. 1998; 35(1):127-32. [PMID: 9499713]

59. Reiss AL, Hennessey JG, Rubin M, Beach L, Abrams MT, Warsofsky IS, Liu AM, Links JM. Reliability and validity of an algorithm for fuzzy tissue segmentation of MRI. J Comput Assist Tomogr. 1998;22(3):471-79. [PMID: 9606391]

60. Kates WR, Warsofsky IS, Patwardhan A, Abrams MT, Liu AM, Naidu S, Kaufmann WE, Reiss AL. Automated Talairach atlas-based parcellation and measurement of cerebral lobes in children. Psychiatry Res. 1999;91(1):11-30. [PMID: 10496689]

61. Talairach J, Tournoux P. Co-planar stereotaxic atlas of the human brain: 3-Dimensional proportional system: An approach to cerebral imaging. New York (NY): Thieme Medical Publishers; 1988.

62. Huster RJ, Westerhausen R, Kreuder F, Schweiger E, Wittling W. Morphologic asymmetry of the human anterior cingulate cortex. Neuroimage. 2007;34(3):888-95. [PMID: 17161625]

63. Paus T, Tomaiuolo F, Otaky N, MacDonald D, Petrides M, Atlas J, Morris R, Evans AC. Human cingulate and paracingulate sulci: pattern, variability, asymmetry, and probabilistic map. Cereb Cortex. 1996;6(2):207-14. [PMID: 8670651$]$

64. Fornito A, Whittle S, Wood SJ, Velakoulis D, Pantelis C, Yucel $\mathrm{M}$. The influence of sulcal variability on morphometry of the human anterior cingulate and paracingulate cortex. Neuroimage. 2006;33(3):843-54. [PMID: 16996751]

65. Rauch SL, Shin LM, Phelps EA. Neurocircuitry models of posttraumatic stress disorder and extinction: human neuroimaging research-Past, present, and future. Biol Psychiatry. 2006;60(4):376-82. [PMID: 16919525]

66. Samuelson KW, Neylan TC, Metzler TJ, Lenoci M, Rothlind J, Henn-Haase C, Choucroun G, Weiner MW, Marmar CR. Neuropsychological functioning in posttraumatic stress disorder and alcohol abuse. Neuropsychology. 2006;20(6): 716-26. [PMID: 17100516] 
67. Woodward SH, Kaloupek DG, Streeter CC, Kimble MO, Reiss AL, Eliez S, Wald LL, Renshaw PF, Frederick BB, Lane B, Sheikh JI, Stegman WK, Kutter CJ, Stewart LP, Prestel RS, Arsenault NJ. Brain, skull, and cerebrospinal fluid volumes in adult posttraumatic stress disorder. J Trauma Stress. 2007;20(5):763-74. [PMID: 17955544]

68. De Meersman RE, Stein PK. Vagal modulation and aging. Biol Psychol. 2007;74(2):165-73. [PMID: 17045727]

69. Critchley HD, Good CD, Ashburner J, Frackowiak RS, Mathias CJ, Dolan RJ. Changes in cerebral morphology consequent to peripheral autonomic denervation. Neuroimage. 2003;18(4):908-16. [PMID: 12725766]

70. Golding LA, Myers CR, Sinning WE, editors. Y's way to physical fitness: The complete guide to fitness testing and instruction. 3rd ed. Chicago (IL): Human Kinetics Publishers; 1989.

Submitted for publication June 4, 2007. Accepted in revised form October 22, 2007. 